\title{
Effect of mould temperature and melt treatment on properties of an AlSi9 cast alloy Thermal and microstructural investigations
}

\author{
Badiâ AIT EL HAJ, Aboubakr BOUAYAD, Mohammed ALAMI \\ Laboratory of Mechanics, Energetics and Materials \\ Ecole Nationale Supérieure d'Arts et Métiers (ENSAM), Moulay Ismaïl University (UMI) Meknes, \\ Morocco \\ E-mail address: aitelhaj.badia@gmail.com, a.bouayad@ensam-umi.ac.ma, \\ alami_simed@hotmail.com
}

\begin{abstract}
Keywords: Al-Si alloy, tatur specimen, grain refinement, thermal analysis, cooling rate, mould temperature, Secondary Dendrite Arm Spacing (SDAS).
\end{abstract}

\begin{abstract}
In this study we used the cast TATUR samples that promotes the formation of an AlSi alloy porosity through a variable temperature gradient from top to bottom of the specimen. The die (permanent mold) was instrumented by thermocouples in order to follow the cooling of the specimen in several emplacements. Thermal analyses via cooling curves have been correlated to the microstructural data (SDAS measurement). Samples were cut from all castings and analyzed by optical microscopy in order to get the Secondary Dendrite Arm Spacing (SDAS) variation in function of cooling rates in the casting. The present work shows the effect of various pre-heating mould temperature and melt treatment on secondary dendrite arm spacing.
\end{abstract}

\section{INTRODUCTION}

The silicon aluminum alloys (Al-Si) provide good castability properties, high corrosion resistance and good physical and mechanical properties that are attractive for many industrial applications [1-6].

The cooling rate is important to determine the microstructure of a casting. Increasing the cooling rate reduces the time of solidification and refines the grain size. The solidification time directly affects the ability of the fluid to feed the solidifying interdendritic region. Also, the grain size has a great influence on the pore size and most of the pores are located at the periphery of the grain [7]

In industry, treatment of liquid metal plays an important role in the multiplication of nucleation sites that significantly improve the characteristics of Al-Si alloys [8]. The mechanism of grain refinement is based on the creation of heterogeneous nucleation sites which are dispersed in the liquid metal. The particles added in very small quantity act as nucleation site for the dendrites and thus lead to the reduction of the grain size. It is therefore necessary to create a large number of solidification nuclei which allow refinement of the structure, and consequently improving the mechanical characteristics.

The technique of thermal analysis (following cooling curves of the alloy) is used to monitor the success of the treatment of liquid metal. In fact, the changes in the cooling curve can be correlated to changes in the solidification of the alloy and consequently the microstructures obtained $[9,10]$.

This study was based on the use of the Tatur sample (fig.1) which has, for its geometry, a variable temperature gradient from the top to bottom. The effect of the initial temperature of the mould, the cooling rate and melt treatment on the microstructure of an silicon aluminum alloy using thermal and metallographic analyses (AlSi9) are studied. 


\section{EXPERIMENTAL PROCEDURE}

In this study we used a silicon aluminum alloy whose chemical composition corresponding to average values of three measurements in the sample obtained by the optical spectrometer shown in Table I:

TABLE I. CHEMICAL COMPOSITION OF THE CASTING ALLOY

\begin{tabular}{|l|l|l|l|l|l|l|l|l|l|}
\hline Alloy & Si \% & Mg \% & Fe \% & Cu \% & Zn \% & Mn \% & Ti \% & Pb \% & Al \% \\
\hline AS9 & 8.687 & 0.021 & 0.413 & 0.058 & 0.294 & 0.190 & 0.01 & $<0.001$ & Bal. \\
\hline
\end{tabular}

Titanium is known as grain refiner of proeutectic phase of hypoeutectic Al-Si alloys. The concentration of this element in the alloy and its effect will be explored. The titanium is provided in the form of potassium fluotitanate $\mathrm{K}_{2} \mathrm{TiF}_{6}$.

For these experiments, the alloy was melted in silicon carbide crucibles using a resistive furnace and poured in the metallic mould (Called TATUR). The alloy was melted until the metal reached $730^{\circ} \mathrm{C}$. To be in similar configurations in each experiment, we measure the initial temperature of metal mould. The mould is preheated at two temperatures $150^{\circ} \mathrm{C}$ and $300^{\circ} \mathrm{C}$. Before casting, the cavity of the mould was covered by a layer of a coating (refractory for easily separate the specimen and to protect the mold against thermal shocks).

The variation of temperature during the solidification process is controlled by the introduction of thermocouples dipped in the liquid metal. In order to quantify the effect of the temperature gradient three K-type thermocouples protected by a stainless steel sheath, as shown in fig.2, were located in three different positions named (TOP, MIDDLE, BOTTOM) of the mould cavity and connected to data acquisition and recording system. The cooling curves were drawn by means of dedicated software. Typical temperatures such as temperatures of liquidus and solidus as well as other events related to the solidification of the cast can be determined by analysis of the cooling curves (temperature-time curves) recorded.

To understand the casting solidification process, the microstructure formation facilitates casting and quality control, the analysis of the cooling curves was accomplished by the micrographic analysis. Samples were cut from the bottom to the top by means of a saw as shown in fig.3. To establish the microstructure of the casting, the specimens were ground, polished and etched by Keller's reagent in order to make the observations under an optical microscope.

The microstructure of each sample was examined and analyzed to evaluate the grain size depending on thermal gradient. SDAS measurements were performed using image analysis software. 


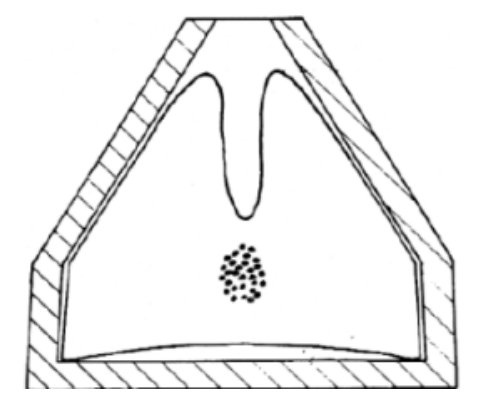

Figure 1. Permanent mould used to cast tatur specimen

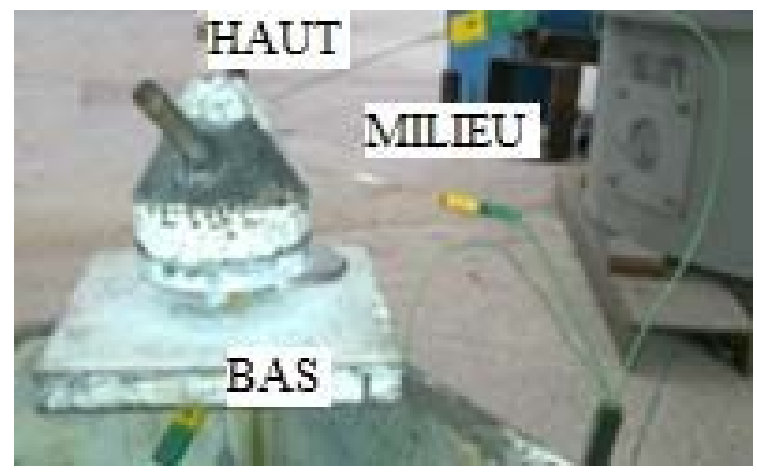

Figure 2. Position of the three thermocouples

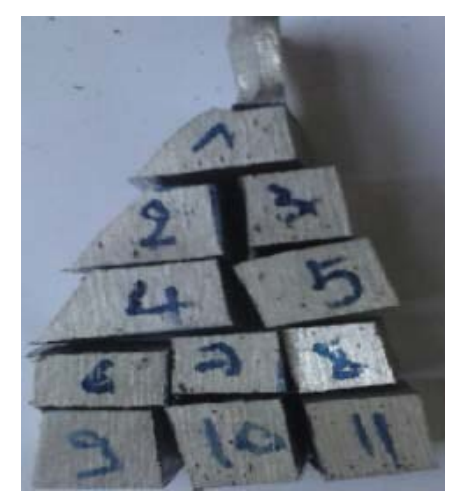

Figure 3. Cut Samples for microstructural investigation

\section{RESULTS AND DISCUSSION}

The cooling curves recorded for the AlSi9 cast alloy for variable mould temperatures and refinement conditions (with or without the grain refiner addition) were used to determine the time of solidification. The latter is defined as the time interval elapsed between the liquidus and solidus temperature. These temperatures were obtained from the first derivative of the cooling curve. These experimental data and other parameters of solidification are presented in Table II.

The fig. 4 shows the variation of the temperature versus time $\mathrm{T}=\mathrm{f}(\mathrm{t})$ and their derivatives $\mathrm{dT} / \mathrm{dt}=\mathrm{f}(\mathrm{t})$. The melt was held at $730^{\circ} \mathrm{C}$. The first peak on the $\mathrm{dT} / \mathrm{dt}=\mathrm{f}(\mathrm{t})$ curve indicates the liquidus temperature. The second peak on $\mathrm{dT} / \mathrm{dt}=\mathrm{f}(\mathrm{t})$ curve shows the solidus temperature. The liquidus peak is releated to the nucleation of $\alpha-\mathrm{Al}$ primary phase.

There was a slight decrease of the liquidus temperature in the region "TOP". In opposition, a slight increase in the liquidus temperature is noticed for refining cast specimens, likely due to increased nucleation sites. In the literature, the increased nucleation temperature is often associated with a decrease in grain size [11]. 
Microstructures of some samples are shown in the fig.5. For all specimens cast in various casting conditions mentioned, the comparison of the microstructure of the samples in the region "UP" to that in the region "MIDDLE", shows that the SDAS is slightly larger in the middle region of the specimen (Fig.6)

The effect of grain refiner on the secondary dendrite arm spacing is small, but it may be noted that it is influenced by the solidification time. When the solidification time is reduced, the SDAS also is decreased [12]. A larger solidification time increases SDAS [13]. The grain refinement affects the morphology of the dendritic cells that become more globular.

This study shows that the grain refinement accelerates the formation of the eutectic, but has no effect on the eutectic phase.

The effect of grain refinement on the SDAS in the case of the cast poured on the mould preheated at $300{ }^{\circ} \mathrm{C}$ is less pronounced.

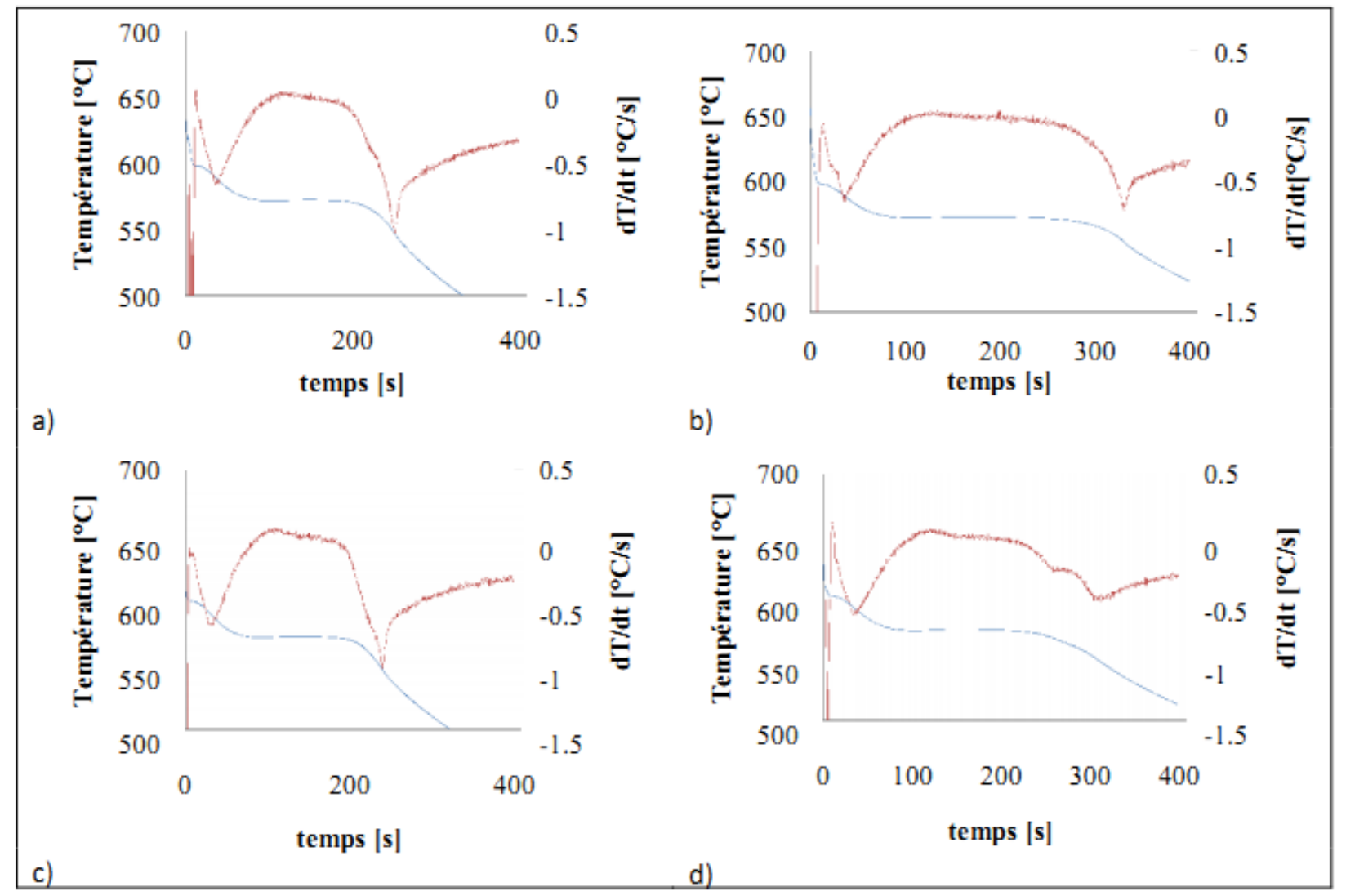

Figure 4. Cooling curves and first derivatives in the region «BOTTOM» for: a) Tmould $=150^{\circ} \mathrm{C}$ without refinement , b) Tmould $=300^{\circ} \mathrm{C}$ without refinement, c) Tmould $=150^{\circ} \mathrm{C}$ with refinement, d) $\mathrm{T}$ mould $=300^{\circ} \mathrm{C}$ with refinement

TABLE II. EXPERIMENTAL DATA FROM THERMAL ANALYSES

\begin{tabular}{|c|c|c|c|c|c|c|c|}
\hline & & & $\begin{array}{c}\text { Liquidus } \\
\text { temperature } \\
\left({ }^{\circ} \mathrm{C}\right)\end{array}$ & $\begin{array}{c}\text { Solidus } \\
\text { temperature } \\
\left({ }^{\circ} \mathbf{C}\right)\end{array}$ & $\begin{array}{l}\text { Solidification } \\
\text { time (s) }\end{array}$ & $\begin{array}{c}\text { Eutectic } \\
\text { duration (s) }\end{array}$ & $\begin{array}{c}\text { Eutectic } \\
\text { temperature }\left({ }^{\circ} \mathrm{C}\right)\end{array}$ \\
\hline \multirow{6}{*}{ 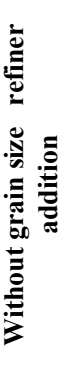 } & \multirow{3}{*}{ 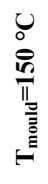 } & TOP & 592,9 & 542,2 & 247 & 140 & 569.2 \\
\hline & & MIDDLE & 598,9 & 548,6 & 239.5 & 125.5 & 572.7 \\
\hline & & ВОТТОМ & 598.3 & 546,5 & 240 & 119 & 572.0 \\
\hline & \multirow{3}{*}{ U. } & TOP & 593,1 & 546,9 & 325,5 & 214 & 568.2 \\
\hline & & MIDDLE & 598,1 & 555,4 & 318 & 206.5 & 572.1 \\
\hline & & оттом & 598,1 & 553,9 & 317 & 192 & 572.3 \\
\hline
\end{tabular}




\begin{tabular}{|c|c|c|c|c|c|c|c|}
\hline \multirow{6}{*}{ 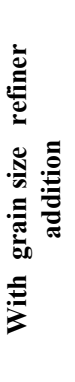 } & \multirow{3}{*}{ 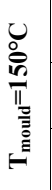 } & TOP & 596,3 & 531,7 & 248 & - & 569.8 \\
\hline & & MIDDLE & 595,8 & 537,8 & 243.5 & 116.5 & 568.3 \\
\hline & & ВОТТОМ & 599,4 & 545,8 & 235 & 118 & 571.1 \\
\hline & \multirow{3}{*}{ 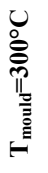 } & TOP & 598.3 & 550,3 & 297 & 197 & 569.1 \\
\hline & & MIDDLE & 601.5 & 554,1 & 296.5 & 157.5 & 572.8 \\
\hline & & BOTTOM & 600.5 & 547,5 & 302.5 & 152.5 & 573 \\
\hline
\end{tabular}

a)

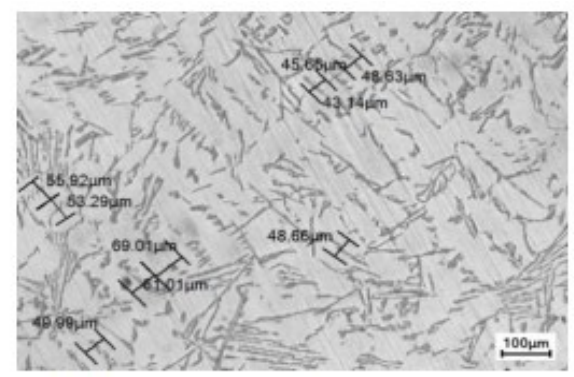

b)

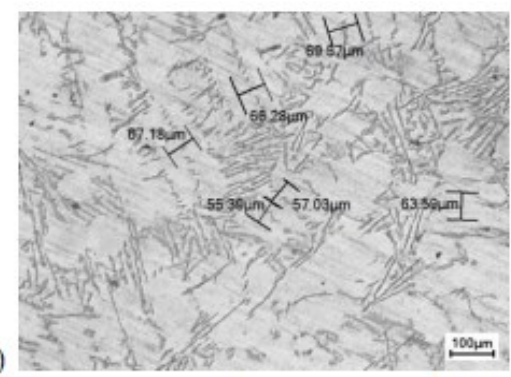

Figure 5. Microstructure of the specimen poured without refinement on preheated mould at $300^{\circ} \mathrm{C}$ in the region: a) «TOP», b) «MIDDLE»

a)

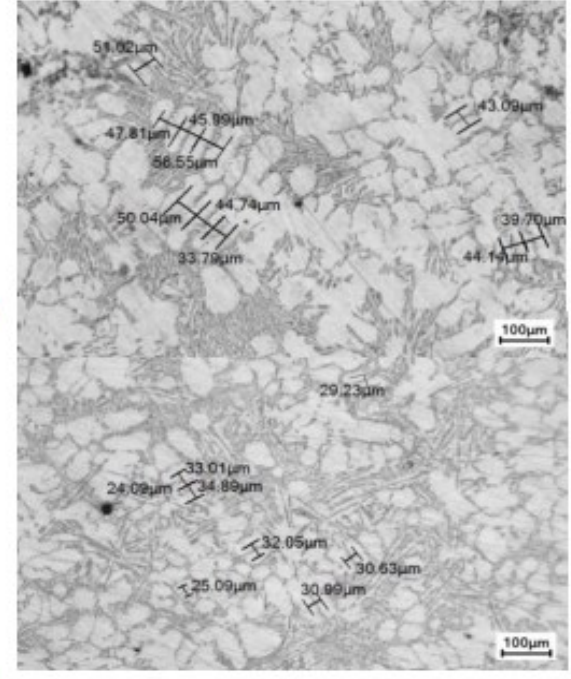

b)

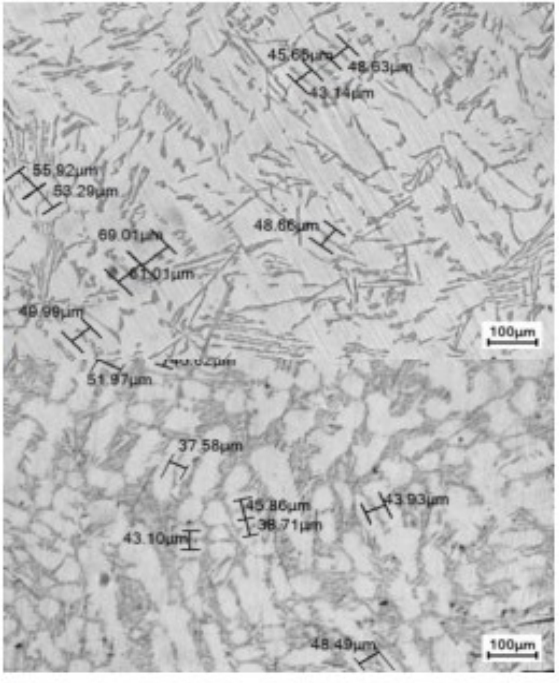

d)

Figure 6. SDAS measurements in the « TOP » region: a) $\mathrm{T}_{\text {mould }}=150^{\circ} \mathrm{C}$ without refinement, b) Tmould $=300^{\circ} \mathrm{C}$ without refinement, c) Tmould $=150^{\circ} \mathrm{C}$ with refinement, d) $\mathrm{Tmould}=300^{\circ} \mathrm{C}$ with refinement

\section{CONCLUSION}

The effect of the mould temperature, the cooling rate and grain refinement on solidification parameters and on the microstructure of AlSi9 alloy were studied using thermal and metallographic investigations. From experimental results, the following conclusion can be summarized:

- Change in the liquidus temperature revealed in the cooling curve can be used as an indicator of the quality of grain refinement. Consequently, we can use liquidus parameters of the casting before pouring the melt to predict the efficiency of the grain refiner. 
- The decrease of mould temperature from $300^{\circ} \mathrm{C}$ to $150^{\circ} \mathrm{C}$ has led the change of solidification time. SDAS decreases with shorter solidification time. The reduction of SDAS in AlSi9 alloy is caused by the severe decrease of the mould temperature.

- The effect of the mould temperature on the value of SDAS was higher in the presence of the grain refiner. However, the casting poured on preheated mould at $300^{\circ} \mathrm{C}$ showed an uniform distribution of dendrites that can be explained by the combination of the effect of temperature gradient and grain refiner addition.

- Addition of grain refiner to the alloy leads to change in microstructure. Grain refinement has not significant effect on SDAS when the mould is preheated at $300^{\circ} \mathrm{C}$, but it changes dendrite morphology to globular and discontinuous cells.

\section{ACKNOWLEDGMENT}

The authors acknowledge M. Maarad for his invaluable help and support for making the experiments in the foundry.

\section{References}

[1] Ch. Pequet, M. Gremaud, and M. Rappaz, "Modelling of microporosity, macroporosity, and pipe-phrinkage formation during the solidification of alloys using a mushy-zone refinement method: applications to aluminium alloys," Metallurgical and Materials transactions, Vol 33A, pp 2095, 2002.

[2] G. Couturier, J.-L. Desbiolles, M. Rappaz, "a porosity model for multi-gas systems in multi-component alloys," TMS(The Minerals, Metals \& Materials Society), 2006.

[3] Jose Manuel ROZOT, "Modèle prédictif de l'apparition de la microporosité de retrait durant la solidification d'un alliage Aluminium-Silicium," (Ph.D. thesis, Université de BORDEAUX 1), 2005.

[4] Jean-lue BATTAGLIA, "A predictive model for the micro-porosity quantitative in Al-Si alloy," The proceeding of COMSOL Multiphysics User's conference, Paris, 2005.

[5] J. Gilbert Kaufman, Elwin L. Rooy, "Aluminium Alloy Castings: Properties, Processes, and Applications, " ASM International, pp 47-54,2004

[6] A. Reis, Y. Houbaert, Zhian Xu, et al., "Modeling of shrinkage defects during solidification of long and short freezing materials, "Materials processing technology, Vol 202, , pp 428-434,2008.

[7] K.DAVAMI，M.K.BESHARATI，M.SHAYGAN, "Modeling of Solidification Conditions and Melt Treatment on Microporosity Formation,"international journal of mathematics and computers in simulation Issue 2, Vol 2, ,144-151, 2008.

[8] D.G.Mallapur, K.Rajendra Udupa, et al., Influence of grain refiner and modifier on the microstructure and mechanical properties of A356 alloy, International journal of enginneering science and technology, Vol.2(9),pp 4487-4493, 2010.

[9] D.Casari, M.Merlin, G.L.Garagnani, "Effect of different types of refinements on A356 foundry aluminium alloy:thermal and microstructural analyses, " Metallurgical Science and technology, Vol.31-1,pp 24-34, 2013.

[10] M.krupinski, k. Labisz et al., "Derivative thermo-analysis application to assess the cooling rate influence on the microstructure of Al-S alloy cast, " Journal of achievements in materials and manufacturing engineering, Vol.38, Issue 2, pp 115-122, 2010. 
[11] S.G. Shabestari, M. Malekan, "Assessment of the effect of grain refinement on the solidification characteristics of 319 aluminum alloy using thermal analysis, " Journal of Alloys and Compounds, Vol. 492, Issues 1-2, 4, pp. 134-142, 2010.

[12] S.G. Shabestari, M. Malekan, "thermal analysis study of the effect of the cooling rate on the microstructure and solidification parameters of 319 aluminum alloy, Canadian Metallurgical Quarterly Vol 44, No 3, pp. 305-312, 2005.

[13] Amaury Chabod, Yves Gaillard, Gerald ogier, Valérie Buecher, "Validation d'un modèle de porosité par tomographie rayons $\mathrm{X}$, " Editions techniques des industries de la fonderie, Paris, FRANCE (1981-2009), no286, pp. 16-25, 2009. 